\title{
Can AI Become a State Servant? A Case Study of an Intelligent Chatbot Implementation in a Scandinavian Public Service
}

\author{
Anastasiya Henk \\ Nord University Business School \\ anastasiya.henk@nord.no
}

\author{
Frode Nilssen \\ Nord University Business School \\ frode.nilssen@nord.no
}

\begin{abstract}
Will AI shorten or increase amount of jobs? This question took one of the central places in the service literature debates. On the one hand side, the developers of the AI accentuate potential of the application to completely imitate human behaviour and overtake all human responsibilities. On the other hand, service workers and researchers emphasize the importance and uniqueness of a "human touch" in service work. In order to see how AI can affect the jobs of the service workers, we conducted a case study of a public service entity that introduced an intelligent chatbot in its customer centre. Particularly, we looked into how the implementation affects job characteristics (skills variety, task significance, task identity, autonomy, and feedback) of the frontline service workers.
\end{abstract}

\section{Introduction}

Artificial intelligence (AI) developers are marching into the business world, promising to alter business models and customer behaviour, save time and costs, and improve forecasting and customization of the services [1]. They claim that AI mimics human behaviour and demonstrates high level of intelligence [2]. Existing jobs are threatened by the AI's ability to acquire, process, interpret different types of data and learn from them, and make autonomous decisions [3].

To the extent of our knowledge, previous studies investigating the threats of job replacement by the AI driven technologies are still hypothetical and equivocal. For instance, Brougham and Haar's study of employees awareness and attitudes to the potential hypothetical replacement by the existing intelligent technologies shows rather low levels of anxiety and job insecurities. On the contrary, [5] suggest that AI's potential to obscure the borders between biological, digital and physical aspects of the contemporary world explicitly increases the level of fear of frontline workers.

Nowadays, organizations tend to implement narrow AI driven technologies that are still mainly built around single tasks [6] and are targeted towards the reduction of mundane tasks [7]. Hence, the AI provides humans an opportunity to focus on management of relations, creation of customized solutions, shaping of strategies, development of identities, strengthening of intra-organizational relations, or experimenting with innovative ideas [7, 8]. These opportunities call for enhancement and advancement of employees skills and sophistication of existing forms of organizing and control that will take into consideration involvement of intelligent technologies into organizational daily activities [9].

Even though the AI is widely discussed in management and business literature, the academic research on its implementation and application is still fragmented and at the infancy stage [2]. The existing literature can be categorized between technological, which looks into AI deployment and technical insights, and economic that focuses on its economic effects on the contemporary jobs and businesses [5]. Moreover, to the extent of our knowledge, the research on the job transformation connected to the AI is of a hypothetical and predicting nature and still lacks empirical evidence [1].

Within the domain of Information Science (IS) research, the debate regarding the influence of the information technology (IT) on the job transformation still continues in a dual and controversary perspective. On the one hand, some researchers claim that IT shortens the working places by replacing simple singletask jobs. However, the other stream of research suggests that IT creates uncertainties that stretch human learning capabilities and motivate innovation growth [10]. Interestingly, the success or failure of IT implementation are rarely associated with the technical characteristics but rather with job and process transformation [11]. In this paper we go beyond the scope of a single technology that is designed to support companies in decision making or optimization of their processes. We look into the system of technologies that has an ability to process and learn from the data and has a potential to make its autonomous decisions.

Manufacturing sector turned out to be more sensitive to the AI implementation due to the wide number of tasks and operations that can be fully 
automatized and performed by robots or intelligent applications. Automation of production lines and replacement of manufacturing jobs by robots has already proven its efficiency and effectiveness [12]. However, the issue at the stake is whether robotization and artificial intelligence can replace service jobs that require personal interaction with the customers? Therefore, in this paper we address the following research question: How does implementation of the AI transforms jobs of the service frontline workers?

In order to answer the abovementioned research question we applied the job characteristics model [13, 14] that focuses on meaningfulness, responsibility of the outcomes and awareness of an actual outcome of the job. We used a single case study of a Scandinavian Public Service (SPS) that provides financial and professional support to the population in challenging life situations. The SPS has introduced an intelligent chatbot Fredrick to address customers' inquiries related to the financial support applications.

This paper contributes in several ways. First, it looks into how AI transforms job characteristics and contributes to the debate whether AI will replace humans or create new jobs. Particularly, it explains the potential deficiencies of the AI and the need for human presence in a service work. Further, using a dual perspective on the job characteristics (frontline worker vs manager), we explain how managerial practices change in response to the change in job characteristics caused by the AI system implementation [15]. Besides, the paper provides an insight from a public service organization, that prioritizes cost and time reduction over gaining a competitive advantage or creation of unique customer experiences.

The paper is structured in the following way: in the next section we present a conceptual framework of the paper and discuss the literature on artificial intelligence and job characteristics. Further, we present our methodological choices and present the case of the Scandinavian Public Service and how it has adopted an intelligent chatbot to reduce time and costs in the customer centre. Subsequently, we present and discuss our empirical findings connected to the changes in job characteristics, and illustrate how these changes affected both jobs of the frontline service workers and managerial practices. Finally, we outline the limitations of the study and suggest directions for further research.

\section{Literature review}

\subsection{Artificial intelligence and job transformation}

When the literature relatively agrees on the definition of the AI that is "systems's ability to interpret external data correctly, to learn from such data, and to use those learnings [machine learning] to achieve specific goals through flexible adaptation" [2:17], the growing body of knowledge on AI remains unstructured and not interrelated. Particularly, the academic research within the field is dedicated to the potential advantages and challenges of the AI implementation and the technical side of AI application development $[1,2]$.

Traditionally, AI is categorized into two types, namely narrow AI, which is focused within one specialized domain of information, and general AI, which has the ability to learn into new domains. Narrow AI is more frequently implemented in the companies and typically performs only a single task. For instance, AI in medicine helps frontline workers to be more efficient and optimize their routines, e.g. by identification of abnormalities on radiological tests, however it still does not overtake the decision-making making function [6].

Besides all of the potential benefits of the AI, there is a number of challenges associated with it. One of the main barriers to the successful implementation of AI applications relates to a misalignment between the AI model and existing organizational technology architecture [16]. The authors explain the failure of the integration by the lack of "AIOps" or "Artificial Intelligence Operations" that refer to "building, integrating, testing, releasing, deploying, and managing the system to turn the results from AI models into desired insights of the end-users". The AI still lacks accuracy, trust from the users, leads to high stake mistakes (e.g. erroneous medical diagnosis and, as a result, treatment), its "black box" of learning and interpreting processes is "dark" and confusing, and it increases anxiety connected to the possibility of replacement of humans by the AI [17].

Likewise, [18] address the problem of the increased anxiety associated with the AI implementation. The authors addressed the need for development of an overall understanding that $\mathrm{AI}$ is used for people and their improved speed and quality of decision making, with a potential to coaching and training people and creation of new jobs. Particularly, the authors suggest to consider AI as a team member that starts as an assistant that performs simple but time consuming tasks, learns fundamental rules and develops into a potential teammate that unites the knowledge, competences and skills of a team into a collective intelligence. Similarly, [19] address the shift in relation between employees and AI driven technologies from working "alongside" the technology to working "together with" the technology. Based on the ideas 
emerged from their thought experiment, the authors addressed the asymmetric reciprocity in instrumental and symbolic values that appear in human-machine relationship.

Interestingly, but development of machine learning and implementation of $\mathrm{AI}$, does not explicitly require a deep knowledge of computer science. Instead, [8] emphasizes the need for an understanding by the employees of how the machine learning works. Specifically, the author claims employees need an understanding of (i) how machine learning works, particularly focusing on processing the input data into the usable information or other outcome and the differences between human and artificial learning; (ii) application of AI, its potential and limitations; (iii) and ethical borders of AI. Similarly, [20] calls for an increasing understanding of the AI application, specifically, for the CEOs of the potential areas of automatization and further shifts in roles and responsibilities. Particularly, the authors underlies the importance of clarity of inputs and outputs of the autonomous tasks, clear distinction of roles and responsibilities of process and decision owners, structuredness of the service level protocols and coherence of the technical infrastructure. Besides, the author addresses an unresolved dilemma of the sequence of teaching - first humans or AI? In the same vein, [21] explain the success of AI implementation by the creation of inter-departmental teams and involvement of their multidisciplinary skills, integration of data sources and continuous business process management, understanding of AI potential and development of skills to capture the potential promptly.

In order to see how the AI could potential replace the existing jobs, [5] developed a theory of AI job replacement. The main idea of the theory that AI replaces humans rather on the task than job level.
Besides, the authors claim that there are four types of intelligences needed in order to perform a task, namely mechanical, analytical, intuitive, and empathetic. The higher is the level of complexity of a task, the wider is the range of intelligences needed to perform this task. See the summary in the Figure 1.

Besides, the authors assume that development of the Intelligence feature of the artificial intelligence happens gradually and evolving. However, the question remains to what degree the human and machine should be integrated/streamlined and what implications does it have for managerial practices.

The theory suggests that the jobs will be overtaken by the machines, and does not look into the essence of a job and its design. The questions remain whether all the jobs can be mimicked by the artificial intelligence, to what degree the human and machine should be integrated/streamlined, and what implications does it have for managerial practices.

\subsection{Job characteristics}

In order to address the later questions, we suggest to implement the Job Characteristics Model developed by [13] and widely applied in the IS research to look into the changes of job characteristics associated with the implementation of new information technologies. Initially it was developed to study how job characteristics influence job satisfaction, and the mediating effect of the three main critical psychological states, namely experienced meaningfulness of work, experienced responsibility for work outcomes, and knowledge [13, 14]. However, wide application of the model has shown that job characteristics have an influence not only on the job satisfaction, but also on the individual job outcomes and performance [22], thriving [23], responsibility [24], empowerment and organizational commitment

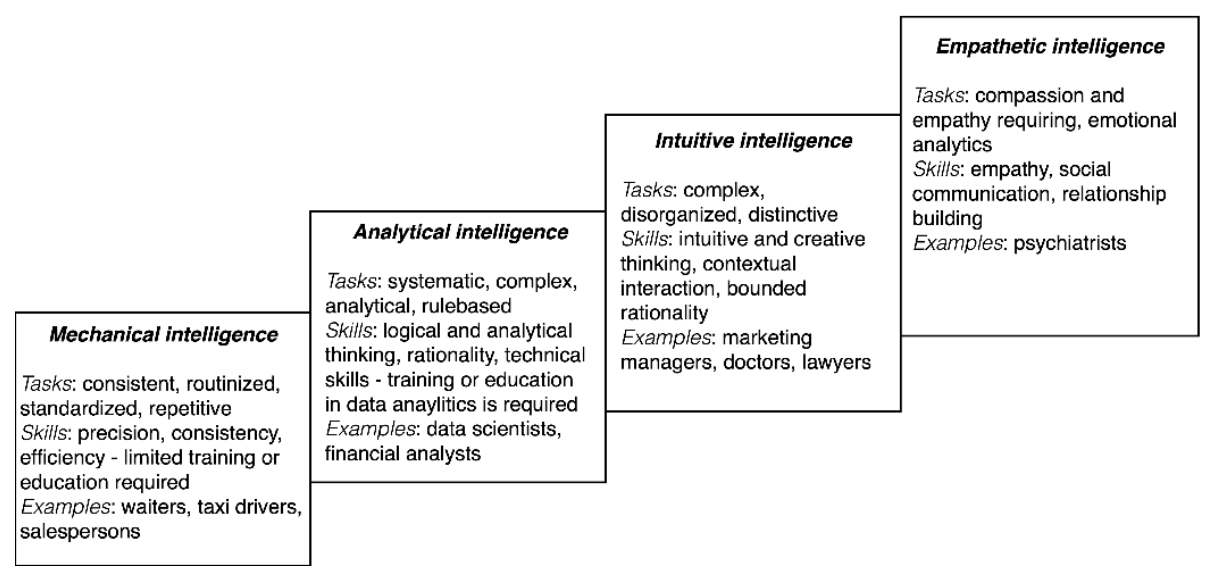

Figure 1. Four types of intelligence [Adopted from [4]] 
[25], and turnover [26, 27]. The model includes five main job characteristics, namely skill variety, task identity, task significance, autonomy, and feedback.

Skill variety is defined as "the degree to which a job requires a variety different activities in carrying out the work, involving the use of a number of different skills and talents of the person" [13:78].

Implementation of a new technology calls for new or advancement of the previous technical skills and competences. Besides, implementation of the new technologies often results in frustration of the employees, their resistance to learn and adopt technology, anxiety connected to new everyday realities, such as larger amounts of data and more complex tasks. All of the aforementioned lead to the decrease in job satisfaction [11]. In turn, assistance in the development of skills related to the implementation of a new technology results in a higher job satisfaction and better performance $[3,28]$. On the contrary, complexity of a technology without provided preliminary training might lead to frustration and impression that while the company is aiming purely at cost reduction, it disrespects it employees that decreases job satisfaction [29].

Task identity is referred as "the degree to which a job requires completion of a "whole" and identifiable piece of work, that is, doing a job from beginning to the end with a visible outcome" [13:78]. The importance of the identity in the IS literature still remains discrepant. Thus when [30] claim that task identity has a very low or almost no influence on the job satisfaction, the studies conducted by [31] and [32] specifically emphasized the importance of task identity for the IT professionals job design. However, the research based on the demographic differences indicated the importance of the task identity specifically to women [33].

Task significance is "the degree to which the job has a substantial impact on the lives of other people, whether those people are in the immediate organization or in the world at large" [13:79]. High level of task significance and value of feedback along with consequent use of IT improves job performance, but requires organizational agility, i.e. ability to address changes of the external environment and assist in improvement of the internal business processes [34]. Thus, information systems and technologies supporting insignificant or irrelevant tasks should be suspended [35].

Autonomy is being addresses as "the degree to which the job provides substantial freedom, independence and discretion to the individual in scheduling the work and in determining the procedures to be used in carrying it out" [13:79]. Redesign of job that affects autonomy of employees leads to the increased anxiety since they feel threatened [11]. Therefore, autonomy is a critical factor that enables intrinsic motivation [36]. Interestingly, that increased need for advanced skills to apply advance IT and, as a result, complexing of IT users job frequently results in increased level of autonomy and simplification of the hierarchical structure within organizations [10]. Autonomy arising from IT implementation is higher in the cultures with low uncertainty avoidance, low power distance and high individualistic countries [15].

Job feedback is defined as "the degree to which carrying out the work activities required by the job provides the individual with direct and clear information about the effectiveness of his or her performance" [13:80]. [31] differentiate between two types of feedback, namely feedback on the job itself and the way it was done, and the feedback on the goals achieved or failed to achieved related to the specific job. Feedback is an important constituent of frontline workers. Implementation of an information technology presumes automatized data collection connected to the employees performance. In turn, employees feel watched and controlled, especially since the "nature" of the feedback changes and becomes more detailed. As a result, it decreases the job satisfaction [11]. However, the balance between social, i.e. feedback based on the personal contact with the manager, and technical, feedback provided by the IT, increase job satisfaction [10].

\section{Methodology}

To study how the jobs of the frontline service workers are being transformed due to the implementation of AI, we chose an inductive single case study approach [37]. The benefits of the case study research refers to its information richness and ability to answer "how" and "why" questions [38, 39]. Moreover, case studies are suitable for research in the fields that are in their early exploratory stages, such as AI research [2]. Furthermore, case studies are applicable for investigation of complex constructs with various complementary links and interrelations due to their multidisciplinary nature and informative abundance, which would be challenging to address by means of other research designs [37].

For the purpose of the study, we used selective theoretical sampling [40] and chose a non-profit organization that provides public services and implemented AI to optimize the jobs of the frontline workers. Particularly, we focused on the jobs of the specialists of the call centre whose responsibilities and tasks were directly affected by the implementation of an intelligent chatbot. In order to perform the case study and ensure credibility of our study [41], we used 
data from three various sources: (i) semi-structured interviews, (ii) internal documents, (iii) publicly available data about the activities of the SPS.

The semi-structured in-depth interviews were conducted with the specialists of the customer centres and their managers and are summarized in Table 1. Semi-structures interviews provide a range of advantages such as possibility for clarification of received information, framing of the course of an interview, personal interaction with the interviewee, possibility to observe the emotions of the participants [39-44]. The interview guides were developed for frontline workers and managers and were built around the influence of AI technology on the five main constructs of the study, i.e. skills variety, task significance, task identity, autonomy and feedback. In addition, the secondary were analysed and the details are presented in Table 2 .

Table 1. Detailed information about the interviews

\begin{tabular}{|c|c|}
\hline Details of the interviews & $\begin{array}{l}\text { Main responsibilities of } \\
\text { the interviewees } \\
\text { (relevant for the purposes } \\
\text { of the study) }\end{array}$ \\
\hline $\begin{array}{l}\text { Interviewees: Chatbot } \\
\text { trainers } \\
\text { Amount of interviews: } 2 \\
\text { Date: January } 2020 \\
\text { Duration: } 40-50 \text { mins } \\
\text { Form: Face-to-face }\end{array}$ & $\begin{array}{l}\text { Frontline workers } \\
\text { Assistance to the } \\
\text { customers with } \\
\text { applications for state } \\
\text { support in various } \\
\text { challenging life situations } \\
\text { Maintenance and training } \\
\text { of Fredrik }\end{array}$ \\
\hline $\begin{array}{l}\text { Interviewees: Specialists } \\
\text { Amount of interviews: } 2 \\
\text { Date: February } 2020 \\
\text { Duration: } 50 \text { mins } \\
\text { Form: Face-to-face }\end{array}$ & $\begin{array}{l}\text { Frontline workers } \\
\text { Assistance to the } \\
\text { customers } \\
\text { applications for state } \\
\text { support in various } \\
\text { challenging life situations }\end{array}$ \\
\hline $\begin{array}{l}\text { Interviewee: Head of the } \\
\text { department (manager) } \\
\text { Date: February } 2020 \\
\text { Duration: } 60 \text { mins } \\
\text { Form: Face-to-face }\end{array}$ & $\begin{array}{l}\text { Management and support } \\
\text { of the specialists team } \\
\text { Training of new } \\
\text { employees } \\
\text { Analysis of customers } \\
\text { feedback } \\
\text { Development } \\
\text { implementation and } \\
\text { improvement initiatives } \\
\text { and actions }\end{array}$ \\
\hline
\end{tabular}

Table 2. Secondary data analyzed in the paper

\begin{tabular}{|l|l|}
\hline Source & Purpose \\
\hline $\begin{array}{l}\text { Specialists } \\
\text { Job }\end{array}$ & $\begin{array}{l}\text { To gain understanding of job } \\
\text { responsibilities and requirements to } \\
\text { skills and competencies required to } \\
\text { perform tasks related to the customer }\end{array}$ \\
\hline
\end{tabular}

\begin{tabular}{|l|l|}
\hline & $\begin{array}{l}\text { services, performance measurement } \\
\text { and reporting mechanisms and what } \\
\text { are the degrees of task significance, } \\
\text { autonomy and feedback }\end{array}$ \\
\hline $\begin{array}{l}\text { Official } \\
\text { webpage }\end{array}$ & $\begin{array}{l}\text { To gain understanding the structure of } \\
\text { SPS, its mission and goals and } \\
\text { understanding of Fredrik's operations } \\
\text { and shortcomings - to understand the } \\
\text { degree of task significance and } \\
\text { autonomy of the intelligent chatbot }\end{array}$ \\
\hline $\begin{array}{l}\text { Annual } \\
\text { reports } 2017,2018,\end{array}$ & $\begin{array}{l}\text { To gain understanding of the digital } \\
\text { transformation initiatives of SPS } \\
\text { including Fredrik's implementation: } \\
\text { premises, scale, challenges and plans } \\
\text { for involvement and how they caused } \\
\text { change in skills variety, task } \\
\text { significance, autonomy and feedback }\end{array}$ \\
\hline $\begin{array}{l}\text { National } \\
\text { legislation } \\
\text { challenges of Al implementation in } \\
\text { public entities and how the personal } \\
\text { data of customers is legally protected } \\
\text { and how they affect boundaries of } \\
\text { Fredrik's autonomy }\end{array}$ \\
\hline $\begin{array}{l}\text { To gain understanding of the } \\
\text { consequences of implementation: } \\
\text { challenges and employees perception }\end{array}$ \\
\hline reports
\end{tabular}

In order to analyse the data, we performed, first, a structural coding [45], where we looked into the job characteristics and how they were affected by the AI implementation. Thus, we used the same codes as described in the theoretical section of the paper: skills variety, task significance, task variety, autonomy, and feedback. Further, in the second circle we applied open coding [45], where we were looking into which managerial practices that were transformed due to the changes in the job characteristics.

\section{Preliminary empirical findings}

\subsection{Implementation of the intelligent chatbot Fredrik}

SPS is a state owned public service that is responsible for provision of financial and professional support for the citizens in various challenging life situations. In 2018, following the governmental strategy for digitalization of the public sector, it introduced an intelligent chatbot Fredrik to assist in processing requests for financial support from population. Besides, the SPS has redesigned its webpage to make it more user friendly and decrease the amount of physical meetings in local offices and human involvement into the customer requests.

Fredrik has a capacity to deal with 1000 requests at a time with potential for further improvement. In 2019, he responded to approximately 400 inquiries per day, 
whereas $40 \%$ of requests were processed and finalized directly by Fredrik, $40 \%$ were send further to the manual chats with the specialists of the customer centre, and for the rest $20 \%$ it was suggested to switch the channel of communication. When the request from a customer requires access to his/her personal information, neither chatbot, nor manual chat can be used due to the restrictions to the personal data access implied by the national legislation. Thus, every digital conversation starts with a reminder not to provide any personal information including customer's name and social security number.

Particularly, Fredrik is dealing with the simple family and employment related cases that do not require much of a human involvement, thus giving an opportunity for the specialists of customer centre to focus on more advanced tasks and tasks involving access to the personal information. Interestingly, the SPS internal statistics shows that time spent per telephone call has increased in average from 4.5 minutes to 7 minutes within the last couple of years. Due to the shortage of the physical offices and introduction of digital improvements, the customers started contacting customer centres with more specified and advanced requests to which employees refer rather like to the "meetings" than just short consultations. The specialists of the customer centre experienced the gradual scepticism of the customers to the digital transformation of Service in general and low level of trust to the newly implemented Fredrik.

Fredrik's skills are being constantly improved as he is constantly being upgraded by the chatbot trainers. Everything that Fredrik is being taught to is categorized into different intents, such as, for instance, "greetings". He is self-learning in the sense that he understands text and in case an unknown word appears during an inquiry, the system will alert and notify the trainers. His knowledge is being upgraded by the sources from different areas of the SPS's activities, and it is vital that customers receive correct information.

Despite the continuous improvement, constant updates and visible breakthroughs, Fredrik has a wide range of limitations. First and foremost, he is lacking basic human understanding, such as being dangerously sick, understanding of the sources of the financial support for the disabled people. He can be trained to show empathy, but it will not be a genuine compassion.

Another Fredrik's limitation refers to prohibition to $\log$ in into the professional system and access personal data of the customers, therefore, he provides only some general information. In addition, he has difficulties to understand non-Scandinavian speakers who refuse to switch to the alternative language or people with low educational level.
Finally, it has been difficult for the managers specialists to understand whether the conversation with Fredrick is finished and whether the customer received the assistance with his inquiry. The latest update provided an opportunity for the customers to give more detailed feedback on Fredrik's performance and finish the conversation by marking it as "resolved", "not resolved" or "irrelevant".

\subsection{Changes for the employees of the customer centre}

Digitization of the SPS core services and implementation of Fredrik lead to the increased occupation of the specialists with more complicated inquiries that require more time, knowledge and experience. Interestingly, one of the specialists when talking about the shift from simple to more complex and specified inquiries to the human specialists assumed that this might also happen due to the general increase in digital erudition and electronic awareness of population:

"People are now more self-assisting electronically, this causes the changes in the questions".

According to another specialist, such a shift in requests was perceived by the employees dissonantly:

"Before, most of the employees experienced their working days as the simple ones. But for someone the days were boring because they were all the same every single day. But, as things get more digitized now and as the chatbot takes away the simplest questions, we are left with the more complicated, demanding questions, which are more intricate and more relevant. And for some of us it is very exciting, while for the others it is very demanding. Then they have lost the nice, quiet and peaceful job they had before then that they could go on autopilot".

In a busy working day with various challenging tasks, specialists often experience difficulties with prioritizing their competence enhancing activities. Moreover, due to the budgetary constraints and intricacy to pause the operations of the SPS, coherent organized training connected not only to the Fredrik's implementation, but also to the digital transformation of the whole SPS, was not provided.

Employees are encouraged to follow the news via the SPS website and internal net. In addition, it is recommended that they take internal courses, and a professional day is held once a year and performed via small meetings if something extraordinary occurs. The competences of the specialists are enhanced by the inter-departmental collaboration and involvement of new team members with new skills and competences. Interestingly, among the skills and competences required for working in the customer centre, both 
manager and specialists named empathy and compassion as the most vital ones:

"In challenging life situations when customers know that it is a machine they are interacting with, they can be a little provoked by it, that it seems a little ridiculous. So I think that genuine compassion is what might be the biggest advantage over the digital technologies".

The main role of the humans is to address the uniqueness of each customer's situation and its context that cannot be achieved by Fredrik due to the prohibition to access personal data and lack of empathy. Moreover, for some customers, such as patients of psychiatric hospitals with mental health conditions, it can be frustrating and confusing to understand that they are communicating with a machine and not a human. When Fredrik just rephrases the answers creating even more confusion, the human specialists have a feeling of the customer, his/her needs and whether the customer has received an understanding regarding his inquiry.

Besides, the specialists need to have both analytical and intuitive understanding of whether or not a customer has received an understanding of the response to his/her inquiry and whether he/she is able to finish his/her application independently, or if he/she needs further and more detailed guidance. Moreover, in comparison to the service jobs where customer satisfaction is positioned in the centre of the organizational activities, the specialists of SPS are allowed and encouraged to make autonomous decisions regarding the communication style with the customer depending on the behaviour of the latter ones.

\subsection{Managerial practices related to the transformation of job}

The digital transformation of the SPS called for the shift of the skills of their specialists. For that reason, the managers needed to reconsider the competence requirements to the new candidates:

"We do not necessarily need the social science background in this type of job, because they are given full training on what they need to know about the various types of support and the services we have. But what we need potential candidates to have are the digital skills".

In order to improve customer related services, the management of SPS developed and implemented the system of feedback on the performance of both human specialists and Fredrik. The evaluation of the specialists' performance focuses on both their general performance and evaluation of separate areas of their activities. Similarly, the evaluation of Fredrik's performance is performed by sending an after-session survey where the customer has a chance to evaluate the degree to which Fredrik has provided assistance to the customer's inquiry. Later, the results of the feedback are discussed with the team, where the focus is dedicated to going through the critical cases, potential for the improvement, and measures that can be taken in order to improve the quality of the services. Interestingly, but the manager does not provide any individual feedback to the specialists. The fact that employees have a high level of competence and high degree of responsibility to meet their competence needs, has led the manager to take a participative management style. Thus the manager provides an example of his interaction with the specialists:

"For now, I have a department with very experienced, independent, autonomous people, so I do not really need to manage them. But I am now getting three new employees, so I have to go more into that controlling role for a period of time, until they are independent enough to be able to stand on their own then. But as of today, I really just need to be present and ask some control questions in relation to what they [specialists] think themselves is smart in a particular challenging case, and usually they have already the answers. But they just need to confirm that I agree that it makes sense, that they are assured it will also resolve the matter on their own."

\section{Discussion}

The empirical findings have shown that implementation of the AI into day-to-day activities transforms rather than completely overtakes existing jobs of service frontline workers. We will further discuss and suggest some propositions for further studies in relation to each job characteristic.

Skills variety. [5] predicted that implementation of AI will result in the need to improve empathetic and intuitive skills of service workers. Indeed, the findings indicate the shift in the tasks and the need for further development of intuitive and empathic skills. This finding seems to be in line with the AI job replacement theory where the overtaking of the tasks happens gradually and in a linear manner. Interestingly, but study shows that this process is affected by budgetary constraints, such as lack of budget for the IT professionals employment, and institutional barriers, such as regulations related to the personal data protection. In fact, even though the AI takes over mechanic and analytical tasks, it still stretches and motivates for further development of analytical skills of the existing specialists.

Preliminary propositions: (a) The degree of mechanic and analytical skills decreases after AI 
implementation. (b) The degree of intuitive and empathic skills increases after the AI implementation.

Implementation of new technologies that involves improvement of the skills and change in the working routines calls for creation of an appropriate organizational culture [20,21]. It should be thoroughly planned to avoid the resistance from the employees and enhanced by the formal communication [46]. However, our study shows that organizational culture was not changed dramatically due to the AI implementation. The chatbot was perceived by the employees as an assisting "new colleague" and not as a breakthrough technology that disrupts everyday activities. The findings demonstrate that instead of creating a new culture, the management of the service created an understanding of what are the nature and limitations of the chatbot. Moreover, the transformational participative leadership style [47] of the manager assisted in the uninterrupted implementation of the application by supporting cross-departmental cooperation and encouraging positive attitude towards the change.

Preliminary proposition: (c) Transformational leadership facilitates skills variety development during the AI implementation process.

Task significance. Implementation of the chatbot in studied organization has transformed the nature of the performed tasks by the specialists of the centre. Thus, instead of dealing with the routinized requests, they have to respond to personalized inquiries that require close human interaction. To the degree of our knowledge, previous research does not show how transforms the task significance but rather focuses mainly on the interrelation between task significance and job performance after implementation [e.g. 34, 35].

Preliminary proposition: (d) The degree of task significance of service jobs increases after the AI implementation.

Task identity. When previous research in IS focuses on the importance of task identity for job satisfaction [e.g. 31-33], to the degree of our knowledge, it does not discuss how the identity changes due to the technology implementation. However, our study demonstrates that the task identity of the service jobs was altered after the introduction of the chatbot. Hence, the tasks that cannot be performed by the chatbot due to the technical, budgetary or institutional constraints, are later accomplished by the specialists.

Preliminary proposition: (e) The degree of task identity of service jobs increases after the AI implementation in public sector.

Autonomy. Implementation of new digital technologies presumes automation of jobs and routinization of tasks that leads to decrease of creativity and freedom of the employees [48]. On the contrary, the introduction of the chatbot and shift to more complex cases resulted in higher degree of responsibility and autonomy of decision making of the specialists in the customer centre.

Preliminary proposition: (f) The degree of autonomy of service workers increases after AI implementation.

Feedback. Previous research suggests that the structure of feedback becomes more detailed in regard to the ways the job tasks were performed [31]. However, our study shows that neither structure nor quality of the feedback changed dramatically due to the implementation of the chatbot. Such finding can be explained by the fact that the implementation was not connected to the ways the information is processed in the service. Instead, it created additional managerial complexity related to the development and management of two feedback systems, whereas one is aimed at evaluation of specialists performance and another at the evaluation of the chatbot performance.

\section{Conclusions}

Addressing the question how the service jobs are affected by the implementation of the AI, this study makes several contributions. First, it demonstrates empirically the shift in the importance of required competences for the service workers from mechanical towards intuitive and compassionate ones. At the same, it still underlies the importance of further development of the analytical skills and addresses the factors influencing the job replacement process, such as budgetary constraints or institutional regulations. Besides, the paper indicates the importance of transformational leadership and managerial involvement into the change process for the ongoing skills development. Further, study shows how increases the degree of task significance and task identity after the introduction of the chatbot. Finally, the paper reveals how implementation of AI facilitates creativity and autonomy of the service workers.

This paper is a work-in-progress, and has a number of limitations and directions for further studies. First, it looks into the narrow AI application that was designed to process the tasks related to the single area of activities. Besides, its intelligence is still in an early stage. Thus, further research should look into more developed and preferably general AI applications. Moreover, in our paper we deployed the JCM [13, 14] perspective to understand which aspects of job content are affected by the AI implementation. However, further studies using the JCM could explore how AI implementation affects employees satisfaction. Alternatively future studies could investigate the 
change in organizational outcomes, e.g. strategic response or operational performance, using the Job Demands-Resources model [49]. The model explains relations between psychological, social and organizational resources, and organizational outcomes. Further research should also shed light on how AI application influences organizational operations and performance in a long-term perspective, since transformation is a continuous process and AI developers promise the revolutionary benefits of its application in the long run [2]. Thus, more empirical evidence along with preferably longitudinal research designs will be beneficial for the field. Furthermore, future research could benefit from studies expanding the understanding of how the employees treat and build partnership the AI driven technologies and whether this relationship affects human identity or reciprocating in their human-human relationship [19].

Furthermore, the paper uses the perspective of the service providers and does not address the customer perception of the artificial intelligence. Therefore, future studies looking into how, for instance, different groups of customers, including elderly people and people with low digital awareness, treat the communication with digital intelligence. Such study should also help to understand whether the AI is able to provide services on the same level and of the same quality as the frontline service workers. In addition to that, following the ideas of the uncanny valley theory [50], the longitudinal studies could also shed light on whether the customer perception of the AI changes over the time.

This study is designed as a single case study that limits its generalization potential. Further studies applying the job characteristics perspective can be verified in a quantitative study. It can test the suggested propositions or outline how implementation of artificial intelligence influences job satisfaction of the employees who have to switch from more simple and routinized to more sophisticated and time consuming tasks.

Finally, the research of the moral issues related to the AI implementation is also important to understand to what degree AI is applicable especially for the customers that are going through challenging life situations. When should be drawn the border between virtual and real? To what extent does the Artificial Intelligence has rights to do mistakes and differ from regular humans? Are there any borders to the AI behaviour - what is appropriate and what is not?

\section{References}

[1]. Davenport, T., Guha, A., Grewal, D., and Bressgott, T., "How artificial intelligence will change the future of marketing", Journal of the Academy of Marketing Science, 2020, 48(1): p. 24-42.

[2]. Kaplan, A. and Haenlein, M., "Siri, Siri, in my hand: Who's the fairest in the land? On the interpretations, illustrations, and implications of artificial intelligence", Business Horizons, 2019, 62(1): p. 15-25.

[3]. Munandar, A. and Albab, B. "Disruption of the workforce in the digital era: A smart store case study. in Managing Learning Organization in Industry 4.0", Proceedings of the International Seminar and Conference on Learning Organization (ISCLO 2019), Bandung, Indonesia, October 9-10, 2019, Routledge.

[4]. Brougham, D. and J. Haar, Smart technology, artificial intelligence, robotics, and algorithms (STARA): Employees' perceptions of our future workplace. Journal of Management \& Organization, 2018, 24(2): p. 239-257.

[5]. Huang, M.-H. and Rust, R.T. "Artificial Intelligence in Service", Journal of Service Research, 2018, 21(2): p. 155172.

[6]. Kalis, B., Collier, M. and Fu, R., "10 Promising AI Applications in Health Care", Harvard Business Review, 2019, Available Online: https://hbr.org/2018/05/10promising-ai-applications-in-health-care

[7]. Porter, K., "Why AI Won't Replace (Great) Salespeople", in Entrepreneur (Europe). 2017: Available Online: https://www.entrepreneur.com/article/292162

[8]. Martinho-Truswell, E., "3 Questions About AI That Nontechnical Employees Should Be Able to Answer", Harvard Business Review, 2018. Available Online: https://hbr.org/2018/08/3-questions-about-ai-thatnontechnical-employees-should-be-able-to-answer

[9]. Faraj, S., S. Pachidi, and K. Sayegh, Working and organizing in the age of the learning algorithm. Information and Organization, 2018, 28(1): p. 62-70.

[10]. Venkatesh, V., Bala, H. and Sykes, T.A. "Impacts of information and communication technology implementations on employees' jobs in service organizations in India: a multi-method longitudinal field study", Production and Operations Management, 2010. 19(5): p. 591-613.

[11]. Morris, M.G. and Venkatesh, V. "Job Characteristics and Job Satisfaction: Understanding the Role of Enterprise Resource Planning System Implementation", MIS Quarterly, 2010. 34(1): p. 143-161.

[12]. Loten, A., “AI to Drive Job Growth by 2020”, Gartner, in The wall Street Journal, Available Online: https://www.gartner.com/en/newsroom/pressreleases/2017-12-13-gartner-says-by-2020-artificialintelligence-will-create-more-jobs-than-it-eliminates

[13]. Hackman, J.R. and Oldham, G.R. "Development of the job diagnostic survey" Journal of Applied psychology, 1975, 60(2): p. 159.

[14]. Hackman, J.R. and Oldham, G.R. "Work Redesign", 1980, Reading, Mass: Addison-Wesley.

[15]. Andreou, A. N. and Boone, L.W. "The impact of information technology and cultural differences on organizational behavior in the financial services industry" Journal of Intellectual Capital, 2002, 3(3): p. 248-261.

[16]. Tse, T., Esposito, M., Mizuno, T. and Goh, D. "The Dumb Reason Your AI Project Will Fail", Harvard Business Review, 2020, Available Online: 
https://hbr.org/2020/06/the-dumb-reason-your-ai-projectwill-fail

[17]. Voosen, P., "The AI detectives", Science, 2017, 357(6346): p. 22-27.

[18]. Babic, B., Chen, D.L., Evgeniou, T. and Fayard, A.L. "A Better Way to Onboard AI", Harvard Business Review, 2020, July - August 2020.

[19]. Bankins, S. and P. Formosa, When AI meets PC: exploring the implications of workplace social robots and a human-robot psychological contract. European Journal of Work and Organizational Psychology, 2020, 29(2): p. 215229.

[20]. Schrage, M., "4 Models for Using AI to Make Decisions", Harvard Business Review, 2017, Available Online: https://hbr.org/2017/01/4-models-for-using-ai-tomake-decisions

[21]. Zoltners, A.A., Sinha, P.K., Lorimer, S.E. and Shastri, A. "4 Ways Sales Teams Could Get More Value out of AI", Harvard Business Review, 2019, Available Online> https://hbr.org/2019/02/4-ways-sales-teams-could-getmore-value-out-of-ai

[22]. Carayon, P., Hoonakker, P., Marchand, S. and Schwarz, J. "Job characteristics and quality of working life in the IT workforce: The role of gender" in Proceedings of the 2003 SIGMIS conference on Computer personnel research: Freedom in Philadelphia--leveraging differences and diversity in the IT workforce, 2003.

[23]. Jiang, Z., di Milia, L., Jiang, Y. and Jiang, X. "Thriving at work: A mentoring-moderated process linking task identity and autonomy to job satisfaction", Journal of Vocational Behavior, 2020. 118: p. 103373.

[24]. Chen, L.-H., Job satisfaction among information system (IS) personnel. Computers in Human Behavior, 2008. 24(1): p. 105-118.

[25]. Kuo, T.H., Ho, L.-A., Lin, C., Lai, K.-K. "Employee empowerment in a technology advanced work environment", Industrial Management \& Data Systems, 2010.

[26]. Lee, P.C.B., "Turnover of information technology professionals: a contextual model", Accounting, Management and Information Technologies, 2000, 10(2): p. 101-124.

[27]. Lo, J., "The information technology workforce: A review and assessment of voluntary turnover research", Information Systems Frontiers, 2015, 17(2): p. 387-411.

[28]. Ply, J.K., Moore, J.E., Williams, C.K. and Thatcher, J.B. "IS Employee Attitudes and Perceptions at Varying Levels of Software Process Maturity", MIS Quarterly, 2012, 36(2): p. 601-624.

[29]. Nankervis, A. R., Connell, J., and Burgess, J. (Eds.). "The Future of Work in Asia and Beyond: A Technological Revolution Or Evolution?", 2020, Routledge.

[30]. Thatcher, J.B., Stepina, L.P. and Boyle, R.J. "Turnover of Information Technology Workers: Examining Empirically the Influence of Attitudes, Job Characteristics, and External Markets", Journal of Management Information Systems, 2002, 19(3): p. 231-261.

[31]. Gambill, S.E., Clark, W.J. and Wilkes, R.B. "Toward a holistic model of task design for IS professionals", Information \& Management, 2000, 37(5): p. 217-228.
[32]. Newton, S., Schambach, T. and Blanton, J.E. "Nature of work effects on motivation of information technology professionals", AMCIS 2002 Proceedings, 2002: p. 293.

[33]. Hoonakker, P., Marian, A. and Carayon, P. "The Relation between Job Characteristics and Quality of Working Life: The Role of Task Identity to Explain Gender and Job Type Differences", Proceedings of the Human Factors and Ergonomics Society Annual Meeting, 2004, 48(14): p. 1571-1575.

[34]. Chung, S., Lee, K.Y. and Kim, K. "Job performance through mobile enterprise systems: The role of organizational agility, location independence, and task characteristics", Information \& Management, 2014, 51(6): p. 605-617.

[35]. Fürstenau, D., Rothe, H. and Sandner, M. "Leaving the Shadow: A Configurational Approach to Explain Postidentification Outcomes of Shadow IT Systems", Business \& Information Systems Engineering, 2020: p. 1-15.

[36]. Toskin, K. and McCarthy, R.V. "Information Technology Work Value Differences", Journal of Computer Information Systems, 2019: p. 1-9.

[37]. Yin, R.K. "Case study research: design and methods", $5^{\text {th }}$ ed., 2014, Los Angeles: SAGE, 282 pages.

[38]. Eisenhardt, K.M. "Building Theories From Case Study Research. Academy of Management", The Academy of Management Review, 1989, 14(4): p. 532.

[39]. Yin, R.K. "Qualitative research from start to finish", 2011, New York: Guilford Press, 348 p.

[40]. Saunders, M., Lewis, P. and Thornhill, A. "Research methods for business students", $5^{\text {th }}$ ed., 2009, New York: Prentice Hall, 614 p.

[41]. Lincoln, Y.S. and Guba, E.G. "Naturalistic inquiry", 1985, Beverly Hills, Calif: Sage.

[42]. Frankfort-Nachmias, C. and Nachmias, D. "Research methods in the social sciences", $5^{\text {th }}$ ed., 1996, New York: St. Martin's Press. xxii, 600, 17 p.

[43]. Easterby-Smith, M., Thorpe, R. and Jackson, P. "Management research", 4th ed., 2012, Los Angeles ; London: SAGE. xvi, $371 \mathrm{p}$.

[44]. Rugg, G. and Petre, M. "A gentle guide to research methods", 2007, Open University Press: Maidenhead.

[45]. Saldana, J. "The Coding Manual for Qualitative Researchers", 2009, Thousand Oaks, California: Sage Publications Inc.

[46]. Haddad, Carol J. "Employee attitudes toward new technology in a unionized manufacturing plant", Journal of Engineering and Technology Management, 1996, 13(2), p. 145-162.

[47]. Luu, D.T. and Phan, H.V. "The Effects of Transformational Leadership and Job Satisfaction on Commitment to Organisational Change: A ThreeComponent Model Extension Approach", The South East Asian Journal of Management, 2020.

[48]. Bakker, A.B. and E. Demerouti, The job demands-resources model: State of the art. Journal of managerial psychology, 2007.

[49]. Zlotowski, J., Sumioka, H., Nishio, S., Glas, D., Bartneck, C. and Ishiguro, H. "Persistence of the uncanny valley: the influence of repeated interactions and a robot's attitude on its perception", Frontiers in Psychology, 2015, 6(883). 